\title{
EPIDIDYMAL CYST
}

\section{Edin HUSARIĆ ${ }^{1}$, Amir HALILBAŠIĆ́ ${ }^{1}$, Maja KONRAD-ČUSTOVIĆ}
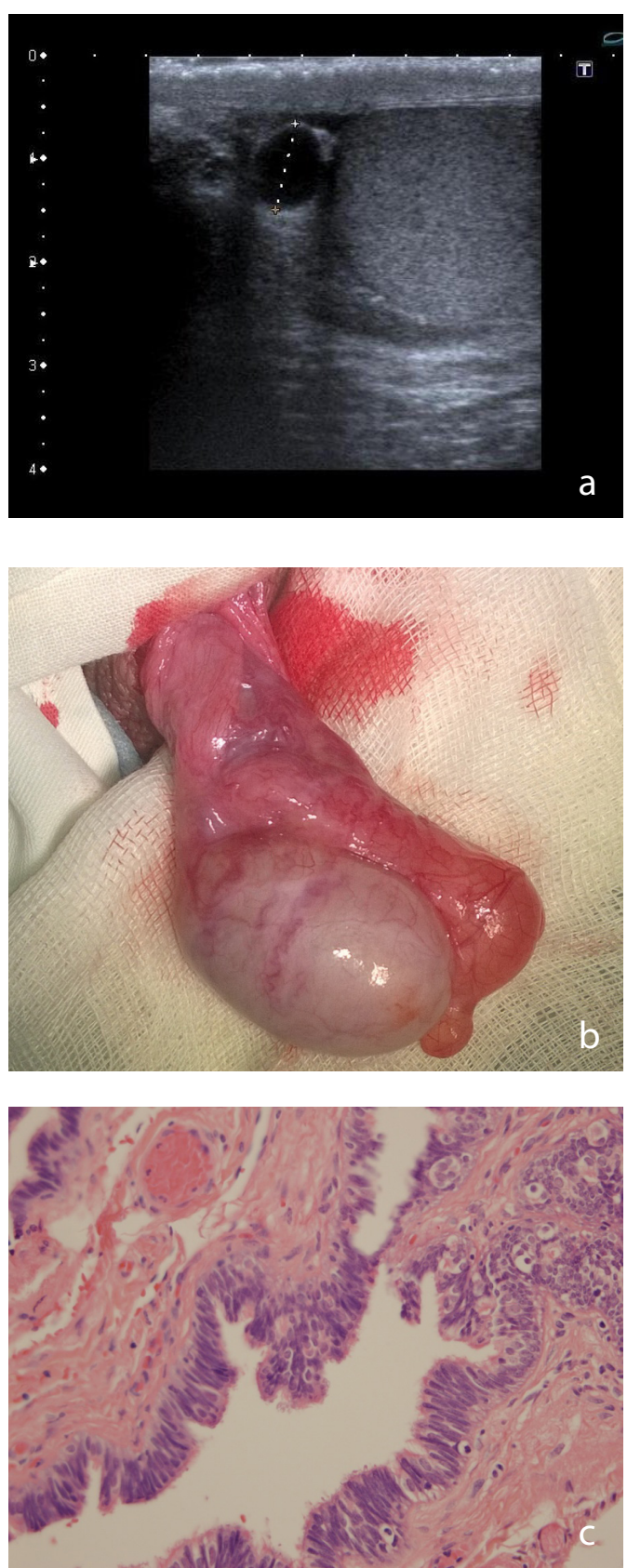

${ }^{1}$ Department of paediatrics, ${ }^{2}$ Deparment of pathology University Clinical Centre Tuzla, Tuzla, Bosnia and Herzegovina

A 12 year old boy was referred to hospital with swelling and discomfort in the right scrotum. Physical examination demonstrated the small mass in the upper pole of the right testis. Urine analysis was unremarkable. Ultrasonography (US) showed an $8 \times 8 \mathrm{~mm}$ cyst in the upper pole of right testis (Panel A). The boy returned after 3 months with the same problem, associated with ongoing pain in the right testis. US, at that time showed an increase in the cyst size with dimensions about $20 \times 15 \mathrm{~mm}$. Based on the history and physical examination, the patient was transferred to operating room. We performed surgery and found the cystic structure within the head of the epididymis, approximately size $20 \times 20 \mathrm{~mm}$. The mass was completely excised (Panel B). On opening, the cyst contained yellowish clear fluid. The cyst was composed of a fibrous wall with congested blood vessels and areas of haemorrhage and necrosis. It was lined partially by ciliated cells (Panel C). The patient was discharged one day after surgery and physical examination was normal during 6 months follow-up. Epididymal cyst (EC) is a benign mass that is relatively common in adults but it is rare in children and its prevalence in children is 5\%-20\%. The diagnosis of EC was made by physical examination and confirmed by US, and confirmed intraoperatively. When EC has been diagnosed using ultrasound, the treatment of these cysts is generally conservative. Surgical excision is 
recommended in children with intractable scrotal pain or if the cyst size continues to increase with serial examination.

Key words: Epididymal cyst - Ultrasonography.

Authors' contributions: Conception and design: EH; Acquisition, analysis and interpretation of data: $\mathrm{AH}$ and $\mathrm{EH}$; Drafting the article: $\mathrm{EH}$, and $\mathrm{MK}$; Revising it critically for important intellectual content: $\mathrm{AH}$ and
EH; Approved final version of the manuscript: $\mathrm{EH}$ and AH.

Conflict of interest: The authors declare that they have no conflict of interest.

\section{Correspondence:} ehusaric@hotmail.com

Tel.: + 38735303 602; Fax.: + 38735250474

Received: May 18, 2016; Accepted: June 19, 2016 